\title{
Evolutionary history determines how plant productivity responds to phylogenetic diversity and species richness
}

The relationship between biodiversity and ecosystem function has received a great deal of attention in ecological research and recent results, from re-analyses, suggest that ecosystem function improves with increases in phylogenetic diversity. However, many of these results have been generalized across a range of different species and clades, and plants with different evolutionary histories could display different relationships between biodiversity and ecosystem function. To experimentally test this hypothesis, we manipulated species richness and phylogenetic diversity using 26 species from two subgenera of the genus Eucalyptus (subgenus Eucalyptus and subgenus Symphyomyrtus). We found that plant biomass (a measurement of ecosystem function) sometimes, but not always, responded to increases in species richness and phylogenetic diversity. Specifically, Symphyomyrtus plants showed a positive response while no comparable effect was observed for Eucalyptus plants, showing that responses to biodiversity can vary across different phylogenetic groups. Our results show that the impacts of evolutionary history may complicate the relationship between the diversity of plant communities and plant biomass. [b] 
1 Evolutionary history determines how plant biomass responds to phylogenetic diversity and

2 species richness

3 Running head: Evolutionary history and ecosystem function

4 Mark A. Genung ${ }^{1 *}$, Jennifer A. Schweitzer ${ }^{1}$, Joseph K. Bailey ${ }^{1}$

\section{Affiliations:}

$6{ }^{1}$ Department of Ecology and Evolutionary Biology, University of Tennessee - Knoxville,

7 Knoxville, Tennessee 37996, USA

8 Email: mgenung@ utk.edu; jen.schweitzer@utk.edu ; joe.bailey@ utk.edu

9 Author Contributions: JAS and JKB designed the study and collected data. MAG, JAS, and

$10 \mathrm{JKB}$ wrote and revised the manuscript.

11 Keywords: Biodiversity, ecosystem function, evolutionary history, phylogeny, species

12 interactions, species richness

13 *Correspondence to:

14 Mark A. Genung

15569 Dabney Hall

16 Knoxville, TN 37996

17 Phone: +001 (865) 946-1764

18 Fax: +001 (865) 974-3067

19 mgenung@utk.edu 
Abstract.

The relationship between biodiversity and ecosystem function has received a great deal of attention in ecological research and recent results, from re-analyses, suggest that ecosystem function improves with increases in phylogenetic diversity. However, many of these results have

24 been generalized across a range of different species and clades, and plants with different evolutionary histories could display different relationships between biodiversity and ecosystem function. To experimentally test this hypothesis, we manipulated species richness and phylogenetic diversity using 26 species from two subgenera of the genus Eucalyptus (subgenus Eucalyptus and subgenus Symphyomyrtus). We found that plant biomass (a measurement of ecosystem function) sometimes, but not always, responded to increases in species richness and phylogenetic diversity. Specifically, Symphyomyrtus plants showed a positive response while no

31 comparable effect was observed for Eucalyptus plants, showing that responses to biodiversity can

32 vary across different phylogenetic groups. Our results show that the impacts of evolutionary

33 history may complicate the relationship between the diversity of plant communities and plant 34 biomass. 


\section{Introduction}

Biodiversity is fundamental to ecosystem services (Millennium Ecosystem Assessment, 2005), and it has been shown that ecosystem function generally improves with increasing species richness (Naeem et al., 1996; Hooper \& Vitousek, 1997; Hector et al., 1999; Troumbis et al., 2000; Tilman et al., 2001). Similarly, losses of species from communities can negatively affect ecosystem services (e.g., Cardinale et al., 2006; 2012; Tilman, Reich \& Isbell 2012). The most common mechanistic explanations for the relationship between biodiversity and ecosystem function (reviewed in Hooper et al., 2005), namely complementarity (e.g., Trenbath, 1974; Vandermeer, 1992) and facilitation (e.g., Callaway, 1995; Valiente-Banuet \& Verdu 2007), are driven by particular plant traits. The importance of traits suggests that evolutionary history, which generates the mechanistic basis for biodiversity effects (trait diversity), may play a large role in influencing ecosystem function (Srivastava, 2012), and in fact recent re-analyses of studies of species-richness experiments have shown that phylogenetic diversity (i.e., the level of phylogenetic relatedness among individuals within a community) can be a better predictor of ecosystem function than species richness (Cadotte, Cardinale \& Oakley, 2008; Cadotte et al. 2009; see Cadotte 2013 for an experimental approach to the same issues). While convergent evolution may give rise to similar traits in lineages that have different evolutionary histories, in general, individuals with different evolutionary histories may respond in different ways to increases in phylogenetic diversity. In other words, because different evolutionary histories give rise to different traits, it is possible that the effects of species richness on ecosystem function will vary across different phylogenetic groups (i.e., clades or other distributions).

Our understanding of how biodiversity drives ecosystem function has been advanced by the recognition that greater phylogenetic diversity may lead to greater ecosystem function, through mechanisms related to complementarity and facilitation. For example, Flynn et al. (2011) 
showed that both functional diversity and phylogenetic diversity predicted plant productivity despite the fact that the correlation between these two metrics was weak or non-existent. The conclusion that functional and phylogenetic diversity separately affect ecosystem function suggests that it may be difficult to identify and measure all traits that are associated with plant productivity or other ecosystem processes, and potentially indicates the existence of complex relationships between plant traits, species richness, and phylogenetic relatedness. Cadotte (2013) helped to illuminate the interactions between species richness and phylogenetic relatedness by showing that the effects of species richness on the productivity of plant mixtures depended on the amount of phylogenetic diversity present in the mixtures. Despite this work, little is known about how phylogenetic diversity interacts with evolutionary history (i.e., evolutionary forces that drive cladogenesis) to impact the traits that affect plant productivity and community interactions.

Studies that manipulate species richness, phylogenetic diversity and phylogenetic relatedness within and among taxa can determine the extent to which each of these factors influence ecosystem function.

Eucalypts are ideal for experimentally addressing the relationship between phylogenetic diversity and ecosystem function because of the high degree of variation in relatedness and the co-occurrence of many of these species in the field. We used 26 native Eucalyptus species in two subgenera, Eucalyptus (10 species) and Symphyomyrtus (16 species), which are distributed in various habitats across a range of elevations in Tasmania, Australia, to examine how phylogeny and biodiversity interact to influence plant growth traits and survival. Hereafter, the terms Eucalyptus and Symphyomyrtus will refer to subgenus identities within the genus Eucalyptus. Individual plants were planted in one of three "species richness" treatments - monocultures, three-species mixtures, or six-species mixtures. We created two mixture types - one from which we randomly drew species from only one subgenus (hereafter "within-subgenus mixtures", for 
both Eucalyptus and Symphyomyrtus), and another treatment for which we drew constituents from both subgenera (hereafter "between-subgenera mixtures"). We use two metrics to represent "biodiversity": 1) "species richness" (SR), which is the number of species present in each pot and 2) "phylogenetic diversity" (PD), as a categorical variable with three levels (monocultures, within-subgenus mixtures, and between-subgenera mixtures). This approach allows us to qualitatively compare the main effects of SR and PD, as well as to test for interactions between these factors and evolutionary history (i.e., subgenus identity). We hypothesized that plants from subgenus Symphyomyrtus would show a stronger response to increases in biodiversity (either SR or PD) because this subgenus has faster growth rates (in the absence of herbivores; Stone et al. 1998) and more foliar N (Wallis et al., 2012) (suggesting adaptation to higher nutrient environments; Hobbie et al., 1992), meaning that plants in this subgenus may benefit more from potential niche partitioning for nutrient acquisition in mixtures.

\section{Materials and Methods}

We established an experiment that used 26 (of 29 total) Tasmanian eucalypt species, planted in species monocultures and mixtures. Of the 26 species, 16 are in subgenus Symphyomyrtus and 10 are in subgenus Eucalyptus. There are 3 series (a phylogenetic designation smaller than subgenus) within Symphyomyrtus and 2 within Eucalyptus (see Senior et al., 2013 for species lists within each series). These phylogenetic classifications are based on a framework created by Booker (2000) with recent molecular data (Diversity Arrays Technology or DArT; Jaccoud et al., 2001) supporting the subgenus- and series-level classifications (McKinnon et al., 2008; Steane et al., 2011; Senior et al., 2013). Seeds from 1-6 individuals, from 1-3 populations of each species were acquired from Forestry Tasmania. We vernalized seeds for 30 days in water (with a drop of dish detergent) and stored the seeds at $4 \mathrm{C}^{\circ}$. Seed from each species were then germinated on the soil surface in separate flats and kept under uniform, moist conditions in a greenhouse. After 10 
weeks, we transplanted the seedlings into monoculture or mixture treatments; more information on the treatments is given later in the methods. At this point seedlings had only barely emerged from the soil and had on average one leaf. The height of these seedlings was less than $5 \mathrm{~cm}$. The seedlings were transplanted into a standard commercial potting mix (Nutricote Grey, Langley Australia Pty Ltd., Welshpool, Western Australia), with 19:2.6:10 (N:P:K) granular fertilizer applied at a rate of $3 \mathrm{~kg} / \mathrm{m}^{3}$. Each large $30 \mathrm{~L}$ (diameter $\sim 35 \mathrm{~cm}$ ) pot contained an equal density of six seedlings. Within each pot, the six individual plants were planted randomly in a circular pattern, after species assignments. The pots of seedlings were grown for 50 days in randomized positions in the glasshouse and then the pots were moved to a fenced, outdoor location on the University of Tasmania campus. Plants were watered daily, and evenly, with automatic sprinkler systems. Weeds in the pots were occasionally removed to minimize their effects on growth of the seedlings.

We measured plant height $(\mathrm{cm})$, stem diameter $(\mathrm{mm})$, and plant survival on individual plants over the course of two months (19 July through 13 September 2011). During this time, temperatures typically range from $5^{\circ}$ to $15^{\circ} \mathrm{C}$ and rainfall is around $50 \mathrm{~mm}$ per month. We quantified the death of individual seedlings, but mortality was $\sim 3 \%$ and therefore all pots were utilized in the statistical analyses. We measured stem diameter at the base of the plants, just above the soil surface. Our analyses use the height and stem diameter measurements from the final date (13 September 2011). We stress that our results should be interpreted in accordance with the timescale of the study (described above); for example, the growth rates of subgenus Eucalyptus and subgenus Symphyomyrtus are known to vary with ontogeny (and also between greenhouse and field conditions) (Duff et al., 1983). We used height and stem diameter measurements from other Eucalyptus plants to construct an allometric equation that predicted total (combined aboveand belowground together) biomass. We grew three individuals of each of the 26 species and sampled one individual from each species at three different sampling dates to obtain a range of 
132 height and stem diameter measurements (height ranged from 7.2 to $105.0 \mathrm{~cm}$; stem diameter 133 ranged from 1.84 to $10.04 \mathrm{~mm}$ ). This allometric equation explained $86.2 \%$ of the variation in 134 total biomass, and is given here: Total biomass $(\mathrm{g})=($ Height $(\mathrm{mm}) * 0.0129)+($ Stem Diameter $135(\mathrm{~mm}) * 2.8207)+((($ Height $(\mathrm{mm})-577.821) *($ Stem Diameter $(\mathrm{mm})-5.554)) * 0.0042)-$ 136 13.796. Plants that did not survive were given "blank" values for height, stem diameter, and 137 biomass, which were not analyzed.

138 Treatments included species monocultures for all 26 species $(n=2$ for 52 monoculture pots 139 or 312 plants) and different types of mixture pots. Mixtures ( $=34$ pots or 204 plants; combined 140 with monocultures this yields a total of 86 pots or 516 plants of which 502 survived the initial transplanting and were used in the analyses) were created through a random draw of species to create pots with either three or six species; some species mixtures contained plants from only one subgenus, while other species mixtures contained plants from both subgenera (Eucalyptus and Symphyomyrtus). Three-species pots that included species from both subgenera (by necessity) included 4 individuals of a given subgenus and 2 from the other subgenus. Due to the random sampling of species to compose mixtures, six-species pots that included species from both subgenera sometimes included 3 species from a given subgenus and 3 species from the other subgenus (i.e., a 3/3 split), and sometimes a 4/2 split. There were no pots that included a 5/1 split. This process created two "diversity" treatments within the same common garden experiment - a species richness (SR) treatment and a phylogenetic diversity (PD) treatment. By definition, adding species to a species monoculture will increase both SR and PD, and the results should be 152 interpreted in this context (i.e., increases in SR cannot necessarily be interpreted as occurring independently of increases in PD). The levels of PD are: species monocultures, within-subgenus mixtures, and between-subgenera mixtures. Although monocultures and within-subgenus

155 mixtures both contain representatives of only one subgenus, within-subgenus mixtures still 156 display more phylogenetic variation than monocultures because of variation in species 
composition. Within-subgenus mixtures could have either 3 or 6 species, but those species were required to come from one subgenus. Between-subgenera mixtures could have either 3 or 6 species, but both subgenera (Eucalyptus and Symphyomyrtus) were required to be represented. Of the 502 plants, 312 (303 survived) were in monoculture and 190 (185 survived) were in some type of mixture. For SR, 129 (126 survived) plants were in 3-species mixtures, and 61 (59 survived) were in 6-species mixtures. For PD, 167 plants (164 survived) were in withinsubgenus mixtures, and 23 (21 survived) were in between-subgenus mixtures. If SR and PD are considered factorially, then 117 plants (115 survived) were in "3-species, within-subgenus" mixtures, 12 (11 survived) were in "6-species, between-subgenus" mixtures, 50 (49 survived) were in "3-species, within-subgenus" mixtures, and 11 (10 survived) were in "6-species, between-subgenus" mixtures. Our manipulations of PD are broad and categorical; we use "subgenus richness" as a simple measure of the phylogenetic diversity present in the community and our results should be interpreted in this light. Additionally, Australian eucalypt species frequently co-occur, including con-subgeneric species pairs (Parsons \& Rowan, 1968; Rogers \& Westman, 1979) and distribution maps indicate that most species are capable of occupying the same environments (Williams \& Potts, 1996) suggesting species interactions among Eucalyptus are present in natural systems. While 6-species mixtures are likely not the norm in natural settings, we employed 6-species mixtures to test the range of variation that is possible (in terms of response to diversity in neighboring plants) for plants within genus Eucalyptus.

\section{Statistical Methods}

We used two REML (restricted maximum likelihood) models, one for SR and one for PD, to determine whether subgenus identity and biodiversity affected plant performance. The fixed effects for this model were subgenus identity (Eucalyptus or Symphyomyrtus), level of diversity (monocultures, 3-species mixtures, and 6-species mixtures for the SR model; monocultures, within-subgenus mixtures, and between-subgenera mixtures for the PD model), and the 
interaction of subgenus identity and level of diversity. The random effects were pot identity (to control for potential variation across pots) and species identity (nested within subgenus identity; to account for differences across the 26 species). The response variables were plant height, stem diameter, survival, and biomass, at the individual level. We recognize that a 3-way model including SR, PD, and subgenus identity would be useful, but we do not have the sample size (specifically, in the 6-species SR * between-subgenera PD combination) to run a robust 3-way model. Therefore, we stress that our two models should be used to evaluate the effect of SR and subgenus identity or PD and subgenus identity, but should not be used to quantitatively compare how SR and PD affect plant performance. For PD, which was a categorical variable, we used post-hoc contrasts to examine pairwise differences between levels of PD (monocultures, withinsubgenus mixtures, and between-subgenus mixtures). Analyses were carried out in JMP 9.0 and when multiple comparisons were made we controlled the False Discovery Rate (Verhoeven et al., 2005; Pike, 2010) at 0.05. The REML output from JMP 9.0 includes the degrees of freedom that provide the closest match between the $\mathrm{F}$ distribution and the distribution of the test statistic (Kenward \& Rogers 1997).

Because the species composition of the non-monoculture pots had been randomly sampled, we needed to account for the composition of species at each level of species richness (i.e., three- and six-species mixtures) and phylogenetic diversity (i.e., within-subgenus and between-subgenera mixtures). This is because random sampling resulted in variable species composition across different levels of diversity (either SR or PD) and not accounting for this would confound species identity and composition with diversity. For each response variable, we assembled a list of the mean response variable for each species when grown in monoculture, and also assembled a list of the proportional representation of each species in each mixture type (3species mixtures, 6-species mixtures, within-subgenus mixtures, between-subgenera mixtures). For each species, we then the multiplied mean response variable by proportional representation 
207 and summed the values for all species. Finally, we compared the expected values for our random

208 draw of species (calculation described above) with the expected values for diversity treatments in

209 which all species were equally represented (following the methods described above, this expected

210 value is equal to the monoculture mean because the proportional representation of all species

211 would be equivalent under these conditions). We found that the random sampling of species had

212 minimal effects (average of $0.8 \%$ and maximum of $2.4 \%$ difference) on expected values in the

213 mixture pots; a table comparing the difference between "random draw" expectations and "equal

214 representation" expectation for all "trait by diversity level" combinations is attached as a

215 supplementary document (Appendix 1). With respect to SR and PD, the magnitudes of the effects

216 we observe are much greater those described above. Because of this, we argue that our "subgenus

217 * diversity level" models (described in the preceding paragraph) are an acceptable way to analyze

218 this data.

219 Results

As predicted, evolutionary history (subgenus-level differences) mediated the relationship between biodiversity and plant performance. In analyses that classified mixture pots according to species richness (SR), we found that SR and subgenus identity interacted to affect stem diameter, survival, and biomass (Table 1, Figure 1). For stem diameter and biomass, the interactions were driven by a positive response of plants within Symphyomyrtus to increasing SR (stem diameter $+28 \%$ and biomass $+28 \%$, in 6 -species mixtures relative to monocultures), compared with a lesspronounced positive response of plants within Eucalyptus (stem diameter $+6 \%$ and biomass

$227+6 \%$ ). For survival, the interaction was driven by a negative response of plants within Eucalyptus 228 (survival -12\% in 6-species mixtures relative to monocultures) compared to a slightly positive response for plants within Symphyomyrtus (survival $+3 \%$ ). 
232 biomass (Table 1, Figure 2). Pairwise, post-hoc contrasts indicated that the PD * subgenus

233 interaction terms for height, stem diameter and biomass were driven by differences in

234 Symphyomyrtus performance between monocultures and within-subgenus mixtures (Table 2).

235 The effects on height, stem diameter and biomass were positive for Symphyomyrtus (height $+18 \%$

236 in within-subgenus mixtures relative to monocultures, and $+18 \%$ in between-subgenera mixtures

237 relative to monocultures; stem diameter $+25 \% /+28 \%$; biomass $+25 \% /+28 \%$ ) and nearly neutral

238 for Eucalpytus (height $-4 \% /+6 \%$; stem diameter $-2 \% /+6 \%$; biomass $-2 \% /+6 \%$ ). Pairwise, post-

239 hoc contrasts indicated that, for survival, the PD * subgenus interaction was driven by differences

240 in Eucalyptus survival in between-subgenus mixtures relative to monocultures and within-

241 subgenus mixtures (Table 2). Survival of Eucalyptus plants was lower in between-subgenus

242 mixtures relative to monocultures (-4\%) and within-subgenus mixtures (-12\%); survival of

243 Symphyomyrtus plants responded less strongly (-2\% in between-subgenus mixtures, and $+3 \%$ in

244 within-subgenus mixtures, relative to monocultures).

245 Discussion.

246 Both measures of biodiversity ("species richness" and "phylogenetic diversity") had

247 impacts on plant communities. The phylogenetic identity of different groups determined whether

248 increases in biodiversity had a significant effect on a given response variable. For plant height,

249 stem diameter, and biomass, we generally observed a positive response to SR for species within

250 the Symphyomyrtus lineage compared with no response for species within the Eucalyptus lineage

251 (Fig. 1, 2). For plants within Symphyomyrtus (but not Eucalyptus), plant height, stem diameter

252 and biomass were greater in within-subgenus mixtures than in monocultures, but between-

253 subgenera mixtures did not differ from either monocultures or within-subgenus mixtures. These

254 results suggest an inconsistent relationship between PD and plant performance, as increasing

255 dissimilarity from monocultures to within-subgenus mixtures increased plant performance but

256 this positive effect disappeared in between-subgenera mixtures. For plant survival, we found that 
plants within Eucalyptus grown in mixtures (either SR or PD) had higher mortality than plants within Eucalyptus grown in species monocultures. Taken together, our results are a proof-ofconcept that even phenotypically similar, closely related phylogenetic groups may show different responses to varying levels of biodiversity.

Subgenus identity determined how all response variables (plant height, stem diameter, survival, and biomass) responded to growing in mixtures rather than monocultures (see interaction terms in Table 1), indicating that evolution has produced different relationships between biodiversity and plant biomass/survival. Moving past this result, the next interesting question involves understanding why these differences exist and whether they are linked with trait divergence. A number of factors (e.g., degree of sympatry, competition, etc.) can affect rates of trait divergence and there have been calls for alternative evolutionary models that can better apply macro-evolutionary patterns to ecological questions (Cadotte et al., 2009; Mouquet et al., 2012; Srivastava et al., 2012). One possible explanation for differences between Eucalyptus and Symphyomyrtus involves differences in landscape-level aggregation patterns; Eucalyptus species show more clustered distributions while the distributions of Symphyomyrtus species are more disjunct (Williams \& Potts, 1996). Perhaps plants within Eucalyptus are less plastic than plants within Symphyomyrtus, limiting their distribution to certain regions and also limiting their ability to respond to different levels of diversity in the surrounding plant communities, but this is purely speculative. Additionally, species within Symphyomyrtus invest less in defense (Stone et al., 1998) and have more available foliar N (Wallis et al., 2010), two traits which suggest a fastgrowth strategy that is adapted to higher-nutrient environments (Hobbie, 1992); perhaps this strategy enables plants within Symphyomyrtus to benefit more from potential niche partitioning, leading to more nutrient availability, in diverse pots. While we do not have the data to provide a mechanistic explanation of how evolution creates different relationships between biodiversity and plant biomass, it is clear that changes in SR and PD have different effects depending on the 
response variable in question and the phylogenetic identity of the plant on which the response was measured.

Because of the large range in genetic variation between within-subgenus and betweensubgenera mixtures, we expected to find different results for plant biomass and survival when comparing these two types of pots. However, we did not observe greater biomass in twosubgenus pots compared with one-subgenus pots (see post-hoc tests in Fig. 2), suggesting that 1) within-subgenus interactions can create mixture effects of the same magnitude as betweensubgenera interactions, 2) the relationship between biodiversity and ecosystem function may be more accurately represented by the interaction of evolutionary history and PD than by measures of diversity that ignore phylogenetic groups, and 3) some increases in PD do not result in increased ecosystem function. Darwin (1859) stated that closely related plants will compete more intensely; however, recent analyses have shown conflicting results which either support (e.g., Burns \& Strauss, 2011) or contradict (e.g., Cahill, Lamb \& Keddy, 2008; Kunstler et al. 2012) this hypothesis. For subgenus Eucalyptus, our productivity results do not indicate a relationship between phylogenetic relatedness within mixtures (i.e., within-subgenus mixtures vs. betweensubgenera mixtures) and the intensity of competition between them, and our survival results suggest that, if anything, competition is greater between distantly related plants. For subgenus Symphyomyrtus, plants were more productive when growing with less-closely related plants, but this did not lead to an increase in survival. One possible explanation for these patterns is that two distantly related groups could demonstrate patterns of parallel evolution along similar environmental gradients, meaning that distantly related species that occupy similar niches could demonstrate large differences in phylogenetic diversity and yet be strongly competitive. This possibility also serves as an example for why more sophisticated, mathematical models linking phylogenies and ecology are needed, (e.g., Cadotte et al., 2009; Mouquet et al., 2012; Srivastava et al., 2012) as mentioned above. 
et al., 1999; Troumbis et al., 2000; Tilman et al., 2001), our results show that SR can be

positively correlated with increasing plant growth. While other studies (e.g., Tilman et al., 2001;

Kunstler et al., 2012) have shown that different species respond differently to increases in the

biodiversity of interacting species, our results build upon this established framework by focusing

on groups of related species (i.e., subgenera) and experimentally showing that the interaction of

evolutionary history and biodiversity (either SR or PD) can influence contemporary ecological

processes. This interaction is potentially due to evolution driving different patterns of trait

development in different phylogenetic groups, which affects the relative roles of competition and facilitation in mixtures comprised of different subgenera. Given that plant traits play a critical role in driving community and ecosystem-level effects of species richness (Cadotte, Cardinale \& Oakley, 2008; Flynn et al., 2011), and that trait diversification rates can vary tremendously across different phylogenetic groups (Ackerley, 2009), these results may provide a first step for understanding how different evolutionary histories may interact with patterns of biodiversity to shape species interactions. In addition, these results indicate that mixture effects are not simply a general consequence of PD as estimated by neutral molecular genetic variation. Instead, mixture effects depended upon the particular phylogenetic group, the amount of diversity present in a given mixture, and the response variable (i.e., plant biomass or survival). Although it is accepted that evolutionary history plays an important role in generating patterns of biodiversity, our results also identify evolutionary history as a determinant of plant biomass by showing that different phylogenetic groups can show different responses to increasing species richness and phylogenetic diversity.

\section{Acknowledgments}


330 Thanks for University of Tasmania for use of facilities and Naeko Omomo, Camilla Bloomfield, 331 and Justin Bloomfield for help in the greenhouse. 


\section{References}

Ackerley D (2009) Conservatism and diversification of plant functional traits: Evolutionary rates versus phylogenetic signal. Proc Natl Acad Sci USA, 106:19699-19706. (DOI 10.1073/pnas.0901635106.)

Burns JH \& Strauss SY (2011) More closely related species are more ecologically similar in an experimental test. Proc Natl Acad Sci USA, 108:5302-5307. (DOI 10.1073/pnas.1116085108.)

Cadotte MW, Cardinale BJ \& Oakley TH (2008) Evolutionary history and the effect of biodiversity on plant productivity. Proc Natl Acad Sci USA, 105:17012-17017. (DOI 10.1073/pnas.0805962105.)

Cadotte MW, Cavender-Bares J, Tilman D \& Oakley TH (2009) Using phylogenetic, functional and trait diversity to understand patterns of plant community productivity. PLOS ONE, 4:e5695. (DOI 10.1371/journal.pone.0005695.)

Cadotte MW (2013) Experimental evidence that evolutionarily diverse assemblages result in higher productivity. Proc Natl Acad Sci USA, 110:8996-9000. (DOI 10.1073/pnas.1301685110.)

Cahill JF, Lamb SWG \& Keddy PA (2008) Does phylogenetic relatedness influence the strength of competition among vascular plants? Perspect Plant Ecol, 10:41-50. (DOI 10.1016/j.ppees.2007.10.001.)

Callaway RM (1995) Positive interactions among plants. Bot Rev, 61:306-349. (DOI 10.1007/BF02912621.) 
Cardinale BJ, Srivastava DS, Duffy JE, Wright JP, Downing AL, Sankaran M \& Jouseau C (2006) Effects of biodiversity on the functioning of trophic groups and ecosystems. Nature, 443:989-992. (DOI 10.1038/nature05202.)

Cardinale BJ, Duffy JE, Gonzalez A, Hooper DU, Perrings C, Venail P, Narwani A, Mace GM, Tilman D, Wardle DA, Kinzig AP, Daily GC, Loreau M, Grace JB, Larigauderie A, Srivastava DS \& Naeem S (2012) Biodiversity loss and its impact on humanity. Nature, 486:59-67. (DOI 10.1038/nature11148.)

Darwin C (1859) On the origin of species by means of natural selection. London, UK: Murray.

Duff GA, Reid JB \& Jackson WD (1983) The occurrence of mixed stands of the Eucalyptus subgenera Monocalyptus and Symphyomyrtus in southeastern Tasmania. Australian Journal of Ecology, 8:405-414. (DOI 10.1111/j.1442-9993.1983.tb01337.x)

Flynn DFB, Mirotchnick N, Jain M, Palmer MI \& Naeem S (2011) Functional and phylogenetic diversity as predictors of biodiversity-ecosystem function relationships. Ecology, $92: 1573-1581$.

Hector A, Schmid B, Beierkuhnlein C, Caldeira MC, Diemer M, Dimitrakopoulos PG, Finn JA, Freitas H, Giller PS, Good J, Harris R, Hogberg P, Huss-Danell K, Joshi J, Jumpponen A, Korner C, Leadley PW, Loreau M, Minns A, Mulder CPH, O’Donovan G, Otway SJ, Pereira JS, Prinz A, Read DJ, Scherer-Lorenzen M, Schulze ED, Siamantziouras ASD, Spehn EM, Terry AC, Troumbis AY, Woodward FI, Yachi S \& Lawton JH (1999) Plant diversity and productivity experiments in European grasslands. Science, 286:1123-1127. (DOI 10.1126/science.286.5442.1123.) 
Hobbie SE (1992) Effects of plant species on nutrient cycling. Trends in Ecology and Evolution, 7:336-339. (DOI 10.1016/0169-5347(92)90126-V)

Hooper DU \& Vitousek PM (1997) The effects of plant competition and diversity on ecosystem processes. Science, 227:1302-1305. (DOI 10.1126/science.277.5330.1302.)

Hooper DU, Chapin FS, Ewel JJ, Hector A, Inchausti P, Lavorel S, Lawton JH, Lodge DM, Loreau M, Naeem S, Schmid B, Setala H, Symstad AJ, Vandermeer J \& Wardle DA (2005) Effects of biodiversity on ecosystem functioning: a consensus of current knowledge. Ecol Monogr, 75:3-35. (DOI 10.1890/04-0922.)

Kenward MG \& Roger JH (1997) Small sample inference for fixed effects from restricted maximum likelihood. Biometrics, 53:983-997.

Kunstler G, Lavergne S, Courbaud B, Thuiller W, Vieilledent G, Zimmermann NE, Kattge J \& Coomes DA (2012) Competitive interactions between forest trees are driven by species' trait hierarchy, not phylogenetic or functional similarity: implications for forest community assembly. Ecol Lett, 15:831-840. (DOI 10.1111/j.1461-0248.2012.01803.x.)

Millennium Ecosystem Assessment. 2005 Ecosystems and Human Well-Being: Synthesis. Washington, DC: Island Press.

Mouquet N, Devictor V, Meynard CN, Munoz F, Bersier LF, Chave J, Couteron P, Dalecky A, Fontaine C, Gravel D, Hardy OJ, Jabot F, Lavergne S, Leibold M, Mouillot D, Munkemuller T, Pavoine S, Prinzing A, Rodrigues ASL, Rohr RP, Thebault E \& Thuiller W (2012) Ecophylogenetics: advances and perspectives. Biol Rev, 87:769-785. (DOI 10.1111/j.1469-185X.2012.00224.x) 
Naeem S, Hakansson K, Lawton JH, Crawley MJ \& Thompson LJ (1996) Biodiversity and plant productivity in a model assemblage of plant species. Oikos, 76:259-264. (DOI 10.2307/3546198.)

Parsons RF, Rowan JN (1968) Edaphic range and cohabitation of some mallee eucalypts in southeastern Australia. Aust J Bot, 16:109-116. (DOI 10.1071/BT9680109.)

Pike N (2011) Using false discovery rates for multiple comparisons in ecology and evolution. Method Ecol Evol, 2:278-282. (DOI: 10.1111/j.2041-210X.2010.00061.x)

Rogers RW, Westman WE (1979) Niche differentiation and maintenance of genetic identity in cohabiting eucalyptus species. Aust J Ecol, 4:429-439. (DOI 10.1111/j.14429993.1979.tb01571.x.)

Srivastava DS, Cadotte MW, MacDonald AAM, Marushia RG \& Mirotchnick N (2012) Phylogenetic diversity and the functioning of ecosystems. Ecol Lett, 15:637-648. (DOI 10.1111/j.1461-0248.2012.01795.x.)

Stone C, Simpson JA, Gittins R (1998) Differential impact of insect herbivores and fungal pathogens on the Eucalyptus subgenera Symphyomyrtus and Monocalyptus and genus Corymbia. Australian Journal of Botany, 46:723-724. (DOI 10.1071/BT97077.)

Tilman D, Reich PB., Knops J, Wedin D, Mielke T \& Lehman C (2001) Diversity and productivity in a long-term grassland experiment. Science, 294:843-845. (DOI 10.1126/science.1060391.) 
417 Tilman D, Reich PB \& Isbell F (2012) Biodiversity impacts ecosystem productivity as much as 418 resources, disturbance, or herbivory. Proc Natl Acad Sci USA, 109:10394-10397. (DOI $419 \quad$ 10.1073/pnas.1208240109.)

420 Trenbath BR (1974) Neighbor effects in genus Avena 2. Comparison of weed species. J Appl $421 \quad$ Ecol, 11:111-125. (DOI 10.2307/2402009.)

422

423
Valiente-Banuet A \& Verdu M (2007) Facilitation can increase the phylogenetic diversity of plant communities. Ecol Lett, 10:1029-1036. (DOI 10.1111/j.1461-0248.2007.01100.x.)

Vandermeer JH (1992) The ecology of intercropping. Cambridge, UK: Cambridge University Press.

Verhoeven KJF, Simonsen KL \& McIntyre LM (2005) Implementing false discovery rate control: increasing your power. Oikos, 108:643-647. (10.1111/j.0030-1299.2005.13727.x)

Wallis IR, Nicolle D, Foley WJ (2010) Available and not total nitrogen in leaves explains key chemical differences between eucalypt subgenera. Forest Ecology and Management, 260:814-821. (DOI 10.1016/j.foreco.2010.05.040.)

Williams K, Potts B (1996) The natural distribution of Eucalyptus species in Tasmania. Tasforests, 8:39-165. 
Figure Legends.

434 Figure 1. The effects of species richness on plant biomass and survival are dependent on 435 subgenus identity. The species richness manipulation included monocultures (species richness $=$ 436 1), 3-species mixtures, and 6-species mixtures. Plant height (A), stem diameter (B), and biomass 437 (D) responded positively to increasing species richness, but only in subgenus Symphyomyrtus 438 (red lines and points). Survival (C) responded negatively to increasing species richness, but only 439 in subgenus Eucalyptus (black lines and points).

440 Figure 2. The effects of phylogenetic diversity on plant biomass and survival are dependent on 441 subgenus identity. The phylogenetic diversity manipulation included monocultures, within442 subgenus mixtures (with species richness of either 3 or 6 ), and between-subgenera mixtures (with 443 species richness of either 3 or 6). Plant height (A), stem diameter (B), and biomass (D) responded 444 positively to increasing phylogenetic diversity, but only in subgenus Symphyomyrtus. Survival 445 (C) responded negatively to increasing phylogenetic diversity, but only in subgenus Eucalyptus. 446 Letters indicate the results of pairwise contrasts within each subgenus (uppercase for Eucalyptus, 447 lowercase for Symphyomyrtus); groups with different letters are significantly different; to account 448 for multiple tests, we controlled the False Discovery Rate at 0.05 . 


\section{Table $\mathbf{1}_{\text {(on next page) }}$}

Species richness, phylogenetic diversity, and subgenus identity affect plant productivity and survival

"Species richness" is a continuous variable with three levels (1, 3, and 6). "Phylogenetic diversity" is a categorical variable with three levels (species monocultures, within-subgenus mixtures, between-subgenera mixtures). Within-subgenus and between-subgenera mixtures can include 3 or 6 species; the difference is whether those species come from one subgenus or two. The term subgenus describes differences between plants within subgenus Eucalyptus and subgenus Symphyomyrtus. Plant height and stem diameter were continuous responses, and we used REML models with species identity and pot number as random effects. "df Den." is an abbreviation for denominator degrees of freedom, and shows the degrees of freedom that causes the distribution of the test statistic to most closely match the $F$ distribution. Bold, italicized $p$-values are significant at $\alpha=0.05$. 


\begin{tabular}{|c|c|c|c|c|c|c|}
\hline Species Richness Model & Plant He & ght $(485$ & lants) & Stem Di & neter $(4 \varepsilon$ & plants) \\
\hline$(\mathrm{N}=86$ pots $)$ & df Den. & $\mathrm{F}$ & $\mathrm{p}$ & df Den. & $\mathrm{F}$ & $\mathrm{p}$ \\
\hline Species Richness (SR) & 56.12 & 9.029 & 0.004 & 63.63 & 12.300 & 0.001 \\
\hline Subgenus & 23.72 & 0.834 & 0.370 & 24.82 & 2.407 & 0.134 \\
\hline SR * Subgenus & 66.02 & 2.502 & 0.119 & 78.09 & 5.657 & 0.020 \\
\hline & Survi & $1(505 \mathrm{pl}$ & ats) & Biom & ss $(485 \mathrm{p}$ & nts) \\
\hline Species Richness (SR) & 69.77 & 2.572 & 0.113 & 63.65 & 12.193 & 0.001 \\
\hline Subgenus & 21.92 & 2.528 & 0.126 & 24.72 & 2.269 & 0.145 \\
\hline SR * Subgenus & 96.49 & 6.276 & 0.014 & 77.64 & 5.668 & 0.020 \\
\hline Phylogenetic Diversity Model & Plant $\mathrm{H}$ & ght $(485$ & lants) & Stem Di & neter $(4 \varepsilon$ & plants) \\
\hline$(\mathrm{N}=86$ pots $)$ & df Den. & $\mathrm{F}$ & $\mathrm{p}$ & df Den. & $\mathrm{F}$ & \\
\hline Phylogenetic Diversity (PD) & 57.05 & 8.588 & 0.005 & 63.07 & 10.30 & 0.002 \\
\hline Subgenus & 23.63 & 0.804 & 0.379 & 24.52 & 2.360 & 0.137 \\
\hline PD * Subgenus & 99.66 & 4.486 & 0.037 & 123.15 & 7.850 & 0.006 \\
\hline & Survi & $1(505 \mathrm{pl}$ & ats) & Biom & $\operatorname{ss}(485 \mathrm{p}$ & nts) \\
\hline Phylogenetic Diversity (PD) & 68.35 & 8.13 & 0.006 & 63.05 & 10.27 & 0.002 \\
\hline Subgenus & 21.40 & 1.99 & 0.173 & 24.43 & 2.22 & 0.149 \\
\hline PD * Subgenus & 159.84 & 6.18 & 0.014 & 120.94 & 8.11 & 0.005 \\
\hline
\end{tabular}




\section{Table 2 (on next page)}

Pairwise contrasts show that different levels of phylogenetic diversity affect plant traits.

The phylogenetic diversity manipulation included monocultures, within-subgenus mixtures (with species richness of either 3 or 6), and between-subgenera mixtures (with species richness of either 3 or 6 ). The first column describes the two levels of phylogenetic diversity being compared; the next four columns show p-values for different plant traits. The first set of contrasts tests differences for the main effect of phylogenetic diversity. The second and third sets of contrasts test differences for the interactive effect of subgenus identity by phylogenetic diversity. Bold, italicized $p$-values are significant at $\alpha=0.05$ and $(+)$ symbols show which category showed a higher mean value for the listed plant traits. 


\section{Contrast Description}

Monoculture \& Within-Subgenus (+)

Monoculture (+) \& Between-Subgenus

Within-Subgenus $(+)$ \& Between-Subgenus

Eucalyptus Monoculture \&

Within-Subgenus

Eucalyptus Monoculture (+) \&

Between-Subgenus

Eucalyptus Within-Subgenus (+) \&

Between-Subgenus

Symphyomyrtus Monoculture \&

Within-Subgenus $(+)$

Symphyomyrtus Monoculture \& Between-

Subgenus

Symphyomyrtus Within-Subgenus \& Between-

Subgenus

Eucalyptus Monoculture (+) \&

Symphyomyrtus Monoculture

Eucalyptus Within-Subgenus \&

Symphyomyrtus Within-Subgenus

Eucalyptus Between-Subgenus \&

Symphyomyrtus Between-Subgenus $(+)$
Plant Height Stem Diameter

0.004

0.217

0.968

$<0.001$

0.605

0.268

0.708

0.445

$<0.001$

$<0.001$

0.815

0.580

$<0.001$

0.245

0.574

0.141

0.019

0.907

0.020

0.701

0.599

0.608

0.299

0.585

0.666

0.003

0.665 


\section{Figure 1}

Figure 1. The effects of species richness on plant biomass and survival are dependent on subgenus identity.

The species richness manipulation included monocultures (species richness $=1$ ), 3-species mixtures, and 6-species mixtures. Plant height (A), stem diameter (B), and biomass (D) responded positively to increasing species richness, but only in subgenus Symphyomyrtus (open circles and dashed lines). Survival (C) responded negatively to increasing species richness, but only in subgenus Eucalyptus (closed circles and solid lines).
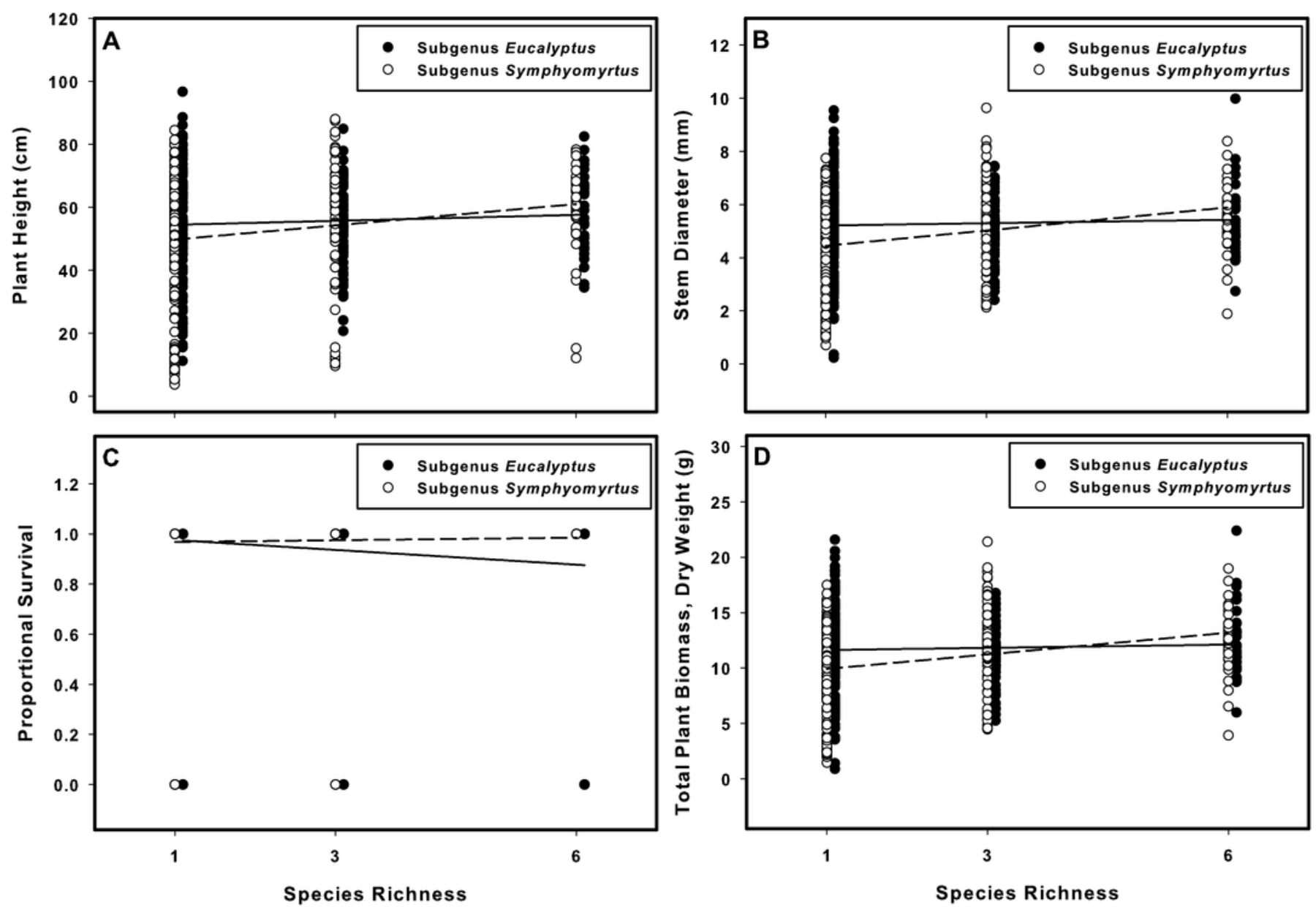


\section{Figure 2}

Figure 2. The effects of phylogenetic diversity on plant biomass and survival are dependent on subgenus identity.

The phylogenetic diversity manipulation included monocultures, within-subgenus mixtures (with species richness of either 3 or 6), and between-subgenera mixtures (with species richness of either 3 or 6$)$. Plant height (A), stem diameter (B), and biomass (D) responded positively to increasing phylogenetic diversity, but only in subgenus Symphyomyrtus. Survival (C) responded negatively to increasing phylogenetic diversity, but only in subgenus Eucalyptus. Letters indicate the results of pairwise contrasts within each subgenus (uppercase for Eucalyptus, lowercase for Symphyomyrtus); groups with different letters are significantly different; to account for multiple tests, we controlled the False Discovery Rate at 0.05 .
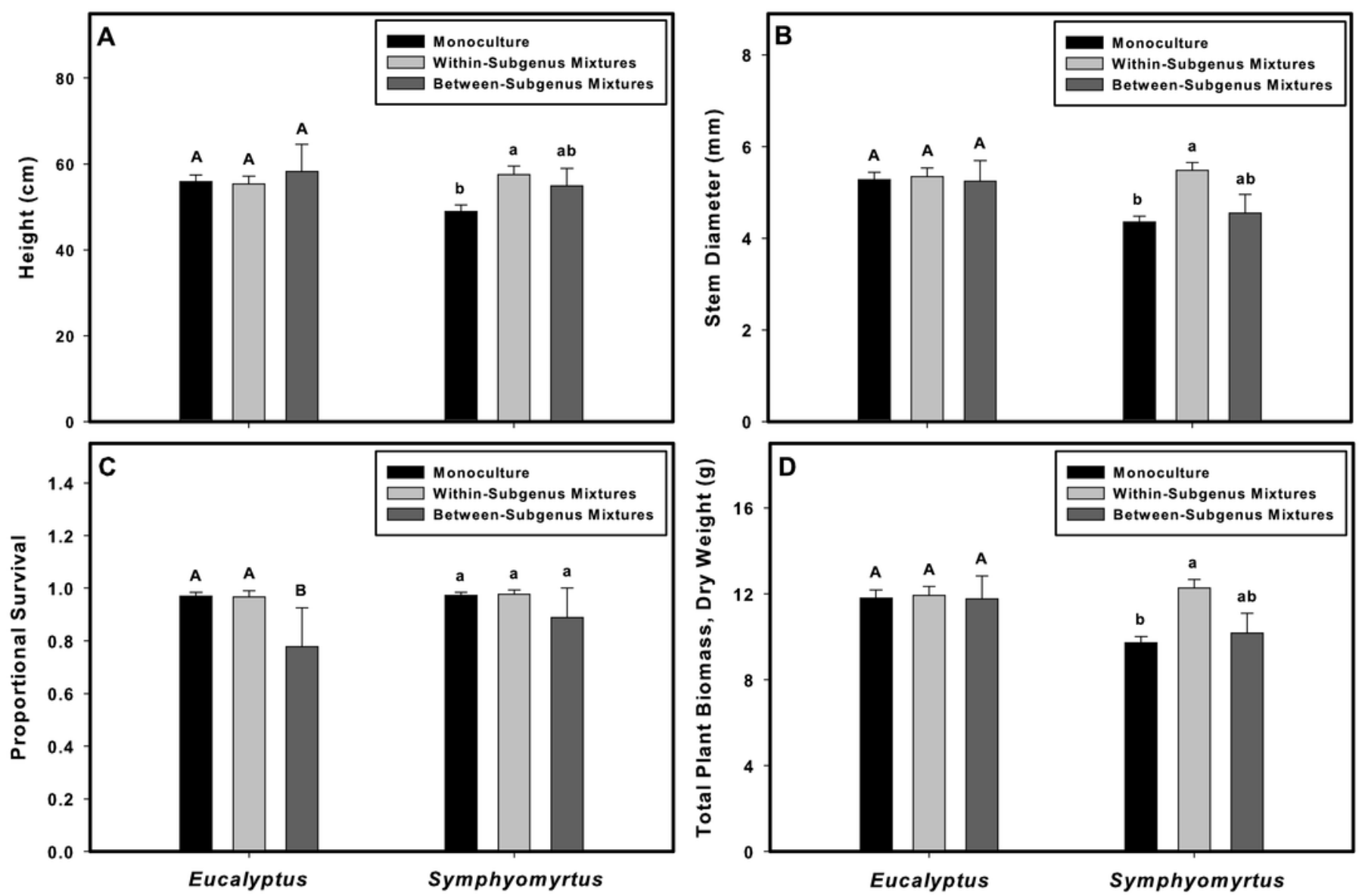